\title{
Effects of septal lesions on social attraction in two subspecies of deer mouse
}

\author{
JAMES M. MacDOUGALL, JAMES W. PENNEBAKER, and MICHAEL STEVENSON \\ Eckerd College, St. Petersburg, Florida 33733
}

\begin{abstract}
Members of two subspecies of deer mouse (Peromyscus maniculatus) that differ in social gregariousness were given septal lesions and tested for pairwise sociability. Gracilis normally a highly social animal, became even more gregarious following septal damage, while bairdi, which normally shows avoidance of social contact, showed further reductions in sociability. The findings lend no support to a previous suggestion that septal lesions enhance sociability generally across species; instead, they suggest that reported increases in social contact in lesioned animals are a secondary consequence of the lesion's tendency to enhance predominant behavior patterns.
\end{abstract}

Several investigators have recently reported that pairs of hooded rats sustaining septal damage evidence heightened social attraction as measured by increased body contact time and decreased average interrat distance (Jonason \& Enloe, 1971; Jonason, Enloe, Contrucci, \& Meyer, 1973; Poplawsky \& Johnson, 1973). These authors suggest that the increased sociability of the lesioned animals arises from a perseverative tendency to engage in prepotent behavior patterns-an explanation consistent with the strong tendency toward contact sociability in undamaged rats (Latané, Nesbitt, Eckman, \& Rodin, 1972) and with the findings of numerous operant experiments reporting response perseveration following septal lesions (McCleary, 1966). Glendenning (1972), in a study attempting to extend the generality of the original Jonason and Enloe findings, reported that pairs of domestic cats sustaining septal lesions showed no increase in body contact time nor any decrease in average pair distance. Thirteen of the 14 lesioned animals did, however, increase the amount of looking behavior directed toward the other member of the pair, a measure which Glendenning classified as "social/passive." Since the looking behavior was not, preoperatively, a high-probability response, Glendenning concluded that spetal damage acts to facilitate social behavior by enhancing a general disposition toward sociability, rather than by enhancing specific high-probability behaviors. According to this interpretation, neurological mechanisms located in the septal region presumably participate directly in the regulation of sociability, however it is expressed in the particular species. If correct, such an interpretation would have considerable theoretical importance. For this

This research was supported by a grant from the Faculty Research and Publications Committee of Eckerd College. Thanks are extended to Ms. Rosemary Hanes for help in the preparation of the figures contained herein. James W. Pennebaker is now at the Psychology Department, University of Texas, Austin, Texas. reason, it seemed desirable to attempt to develop an experimental test which would clearly differentiate between the specific response-facilitation interpretation offered by Jonason and Enloe and others and the more global explanation proposed by Glendenning.

One approach to such a test would be to compare the effects of septal damage on the social behavior of two closely related species, one of which is highly social and one of which evidences active avoidance of social contact. If the effect of the lesion is to generally enhance a disposition toward sociability, then both species should show increased social behavior. If, however, the lesion acts primarily to enhance the expression of predominant behavior patterns, then the lesioned members of the species which actively avoid social contacts should show a further reduction in social behavior. Two subspecies of deer mouse which evidence this pattern of approach and avoidance are Peromyscus maniculatus gracilis and P.m. bairdi. Gracilis is an inhabitant of wooded areas in the northern United States and Canada where it leads a semiarboreal existence; bairdi is a more widely distributed grassland mouse which makes its home under stones and clods and in the burrows of other animals (Foster, 1959). The behavior of these two subspecies has been extensively studied by several authors (Foster, 1959; King, 1969; King, Price, \& Weber, 1968), but most relevant to the present experiment is the unpublished observation by one of the present authors (M. S.) that in an open field, like-sexed strangers of the subspecies gracilis spend a great deal of time in close proximity, while strange bairdi expend most of their efforts avoiding one another. The present experiment utilized this species-specific difference in social behavior to differentiate between the proposed rival hypotheses. Members of each subspecies were given either septal lesions or sham operations and then tested for sociability in an open field using indices similar to those used by Jonason and Enloe (1971) and developed by Latane (1969). 


\section{METHOD}

\section{Subjects}

The subjects were 16 male Peromyscus maniculatus gracilis and 54 male P.m. bairdi, ranging in age from 6 months to 2 years at the beginning of the study. All mice were offspring of stock obtained from the Michigan State University Zoology Department, where both subspecies had been housed under laboratory conditions for several years. The colony was maintained on a 16-h/8-h light-dark schedule, with the dark period beginning at 11:00 p.m. Prior to the experiment, the subjects were housed with a mate or with a like-sexed littermate. At least 1 week prior to surgery, subjects were isolated in separate cages with food and water continuously available. As a result of the generally poor breeding patterns of captive gracilis, considerable difficulty was encountered in obtaining sufficient numbers of adult males for use in the present study. This factor accounts for the large discrepancy in numbers of subjects in the bairdi and gracilis groups.

\section{Apparatus}

The apparatus was a circular open field, similar to the one described by Latane (1969), except that the floor of the field was divided into 69 numbered squares of approximately equal area $\left(50 \mathrm{~cm}^{2}\right)$. The field was $71 \mathrm{~cm}$ in diam, with walls $50 \mathrm{~cm}$ in height. The floor of the field was covered with a transparent plastic sheet to facilitate cleaning following the testing of each subject or pairs of subjects. In order to observe the subjects and to collect data without interfering with their behavior, a Sony videotape television camera was situated above the floor of the field, with the monitor and video recorder located in an adjacent room.

\section{Procedure}

Surgery and histology. Subjects within each subspecies received either a septal lesion or control operation. Septal lesions were produced stereotaxically under Equithesin anesthesia $(.06 \mathrm{cc})$ by passing radio frequency current through a $.5-\mathrm{mm}$ stainless steel electrode insulated with Epoxylite except for
$.5 \mathrm{~mm}$ of the tip. An ear bar connection completed the circuit. Stereotaxic measurements were made in millimeters from bregma, midline, and the horizontal dorsal surface of the skull. The following coordinates were used for the two subspecies of mice: bairdi-A $0.8 \mathrm{~mm}, \quad \mathrm{~L} 0.0 \mathrm{~mm}$, and D $3.4 \mathrm{~mm}$; gracilis-A $1.2 \mathrm{~mm}, \mathrm{~L} 0.0 \mathrm{~mm}$, and D $3.4 \mathrm{~mm}$. Control subjects underwent the same operative procedures, but the electrode was not lowered into the brain.

Following behavioral testing, the subjects were deeply anesthetized with chloroform and decapitated. The posterior section of the brain was exposed, and the entire head was placed in $20 \%$ formalin for 2 to 4 weeks. Following fixation, the brains were extracted and embedded in celloidin. Coronal sections 35 microns thick were taken throughout the extent of the lesion and were stained with cresyl violet. Sections were then projected onto graph paper, where a quantitative index of the size of each lesion was obtained by counting the number of squares occupied by the lesion relative to the area occupied by the entire septum. Lesion size is thus expressed as an average of the percentage damage in four standard planes throughout the septum.

Behavioral testing. The mice were assigned to one of four groups: bairdi control $(\mathrm{N}=14$ pair), bairdi lesion $(\mathrm{N}=13$ pair), gracilis control $(\mathrm{N}=4$ pair), and gracilis lesion $(\mathrm{N}=4$ pair). Within each group, subjects were arbitrarily paired on the basis of order of selection with the restriction that animals were not paired with previous cagemates. Testing began 7 to 10 days following surgery and was conducted between 1:00 p.m. and 5:00 p.m. Each subject was tested in the following way: On Pretest Days 1 and 2, subjects were placed individually in the field for $5 \mathrm{~min}$ in order to adapt them to the testing situation; on Test Days 1, 2, and 3, the assigned pairs within each group were placed in the field together for $5 \mathrm{~min}$.

Before each trial, the mice were transferred in their home cage to a large cardboard box, where the home cage top was removed. The mice were then trapped in an $8.9 \times 8.9 \times 10.2 \mathrm{~cm}$ plastic container and transported in the container to the test room, where they were placed directly in the filed. At no time were the subjects touched or directly held by the experimenter. After placing either the individual subject or pairs of subjects in the
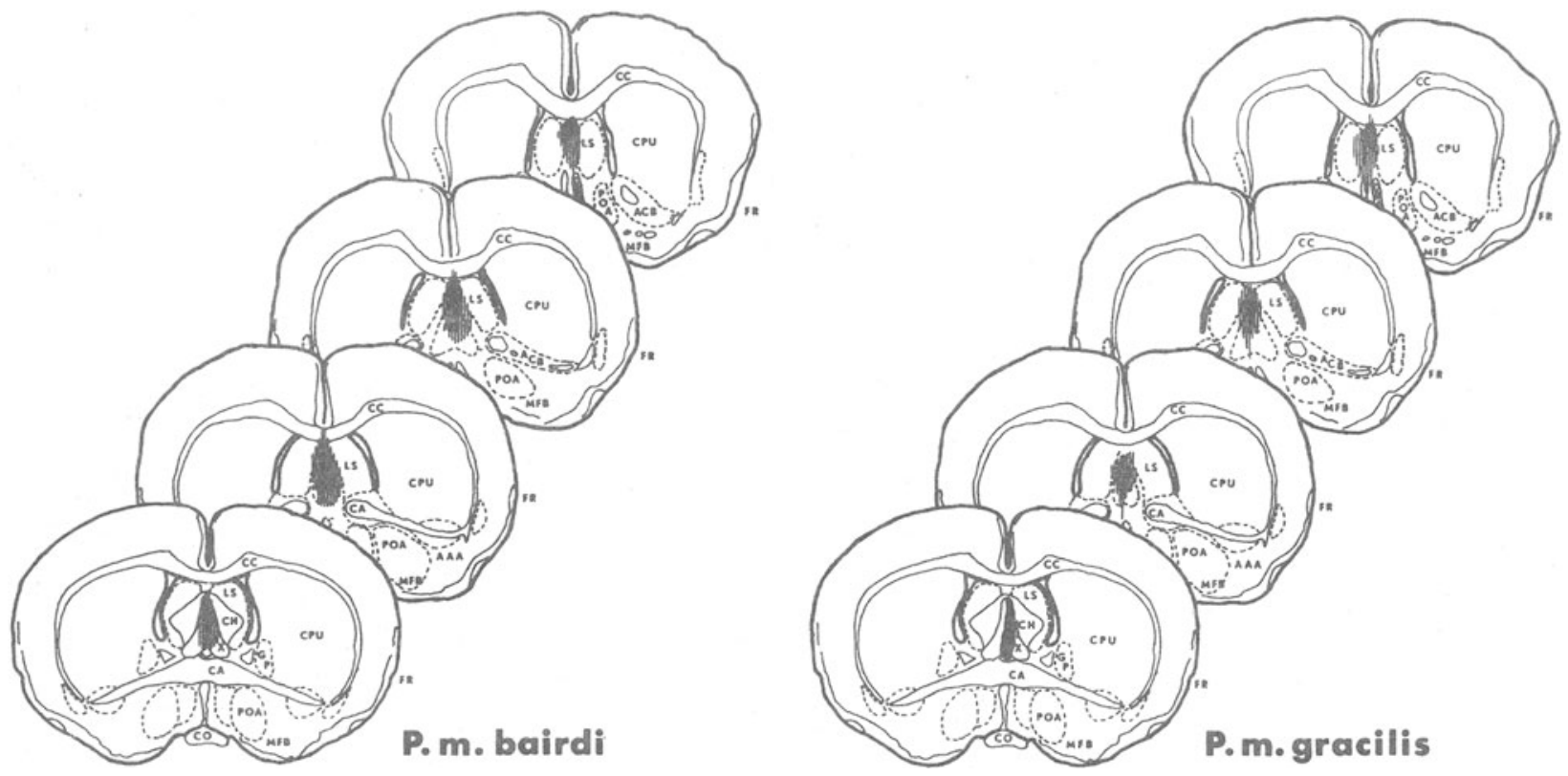

Figure 1. Minimum (solid) and maximum (vertical lines) lesions for bairdi and gracilis subjects. Redrawn from Elefthoriou and Zolouick (1965). 
field, the experimenter left the room and began videotaping the behavior in the field. During adaptation, the experimenter recorded on a sweep clock the total time during which the mouse was immobile (feet stationary). During pair testing, the same clock was used to record total contact time (contact between any body parts except tail).

At the end of the observation period, subjects were returned to the home cage using the same capture and transport technique. The experimenter then returned to the videotape equipment and replayed the entire 5-min test trial. Every $10 \mathrm{sec}$, the tape was stopped, and the location of the mouse, or the pair of mice, was recorded. Location data for pairs of subjects were then converted to distances. Daily counts of fecal bolus production and occurrence of urination were kept for adaptation and test trials, but these measures failed to differentiate any of the groups, and, thus, are not considered.

\section{RESULTS}

\section{Histological Findings}

As can be seen in Figure 1, the septal lesions produced in the present study were small for both subspecies (bairdi: mean volume $=9.9 \%$, range $=5.6 \%-19.2 \%$; gracilis: mean volume $=8.1 \%$, range $=3.3 \%-16.1 \%$, and were predominantly restricted to the medial and dorsomedial portions of the septum. Damage began varying distances posterior to the genu of the corpus callosum and continued caudally to the columns of the fornix. Most lesions were located in the midsagital plane and extended dorsoventrally from the corpus callosum to the ventral third of the septum. Damage to the lateral septal nuclei was minimal, and incidental damage to the overlying cortex and adjacent caudate, fornical, and thalamic structures was minimal or virtually nonexistent. No relationship could be found between lesion size or location and the magnitude of the behavioral effects produced.

\section{Behavioral Findings}

Initial adaptation. In spite of the limited number of P.m. gracilis used in the study, the results are quite clear cut. Informal observation indicated that lesioned gracilis and bairdi evidenced a heightened postoperative responsiveness to stimulation and an increased aggressiveness toward the experimenters which persisted throughout behavioral testing. The magnitude of the effect varied for the two subspecies. The normally more placid gracilis showed smaller increases in reactivity and relatively little aggression; bairdi, however, attacked pencils thrust into their cages and made vigorous efforts to escape when the cage top was removed.

During adaptation to the test apparatus, all groups evidenced a strong tendency to remain in the perimeter of the field. This is presented in Table 1 as the proportion of the 60 time samples across the 2 adaptation days in which subjects were located in squares adjacent to the field walls. The mean proportions for all groups were significantly greater than the expected value of . 33 which is based on the relative
Table 1

Perimeter and Immobility Data for Adaptation Sessions*

\begin{tabular}{|c|c|c|c|c|c|}
\hline \multirow[b]{2}{*}{ Group } & \multirow[b]{2}{*}{$\mathrm{N}$} & \multicolumn{2}{|c|}{$\begin{array}{c}\text { Percentage Time } \\
\text { in Perimeter }\end{array}$} & \multicolumn{2}{|c|}{$\begin{array}{l}\text { Immobility } \\
\text { in Seconds }\end{array}$} \\
\hline & & Mean & SD & Mean & SD \\
\hline \multicolumn{6}{|l|}{ Gracilis } \\
\hline Lesion & 8 & 53.5 & 19.1 & 153.2 & 70.7 \\
\hline Control & 8 & 67.0 & 8.3 & 75.2 & 38.1 \\
\hline \multicolumn{6}{|l|}{ Bairdi } \\
\hline Lesion & 26 & 67.1 & 16.2 & 56.6 & 40.9 \\
\hline Control & 28 & 51.1 & 22.0 & 63.0 & 33.6 \\
\hline
\end{tabular}

*Means and standard deviations are based on data summed across the 60 10-sec time samples for the 2 pretest days.

area occupied by perimeter squares. A 2 by 2 analysis of variance for unequal Ns (Edwards, 1968) indicated no significant main effects for species $(F=.05, \mathrm{df}=1 / 66$, $\mathrm{p}=$ n.s. $)$ or lesion $(\mathrm{F}=.05, \mathrm{df}=1 / 66, \mathrm{p}=$ n.s. $)$, but did reveal a significant interaction of these variables $(\mathrm{F}=7.38, \quad \mathrm{df}=1 / 66, \quad \mathrm{p}<.01) . \quad$ Between-group comparisons using the pooled error term revealed that, of the unlesioned subjects, gracilis showed a significantly greater tendency to remain in the perimeter than did bairdi $(\mathrm{t}=2.02, \mathrm{df}=66, \mathrm{p}<.05)$. This reflected the tendency of many bairdi to engage in stereotyped high-speed twirling which often carried them into the center of the field. Gracilis were much more deliberate in their actions and explored the perimeter in a slow and cautious fashion. However, as can be seen, the two subspecies responded differently to the lesions, bairdi by increasing the time spent in the perimeter $(\mathrm{t}=3.08$, $\mathrm{df}=66, \mathrm{p}<.01)$ and gracilis by decreasing it, although not to a statistically significant degree $(t=1.42, d f=66$, $\mathrm{p}<.20$ ).

Analysis of variance of the immobility data which are also presented in Table 1 revealed significant main effects for species $(\mathrm{F}=22.55, \mathrm{df}=1 / 66, \mathrm{p}<.01)$ and lesion $(\mathrm{F}=7.50, \mathrm{df}=1 / 66, \mathrm{p}<.01)$, and for the interaction component $(\mathrm{F}=11.04$, $\mathrm{df}=1 / 66, \mathrm{p}<.01)$. Group comparisons revealed, however, that the significant effects were largely attributable to the extremely high immobility scores of the lesioned gracilis. Lesioned gracilis differed significantly from all of the other groups $(p<.01$ in all cases $)$. The latter were statistically homogeneous among themselves. Interestingly, a significant portion of the increase in immobility evidenced by the damaged gracilis could be attributed to their strong tendency to orient toward their own reflections on the metal wall. Frequently, animals would remain in a very limited portion of the perimeter, scratching and nosing at their reflected images. Mice in the other conditions also engaged in this behavior occasionally, but clearly it was not a high-probability component of their behavioral repertoire. Instead, these subjects spent much of their time grooming themselves and intermittently darting from spot to spot. Consistent with Foster's (1959) 


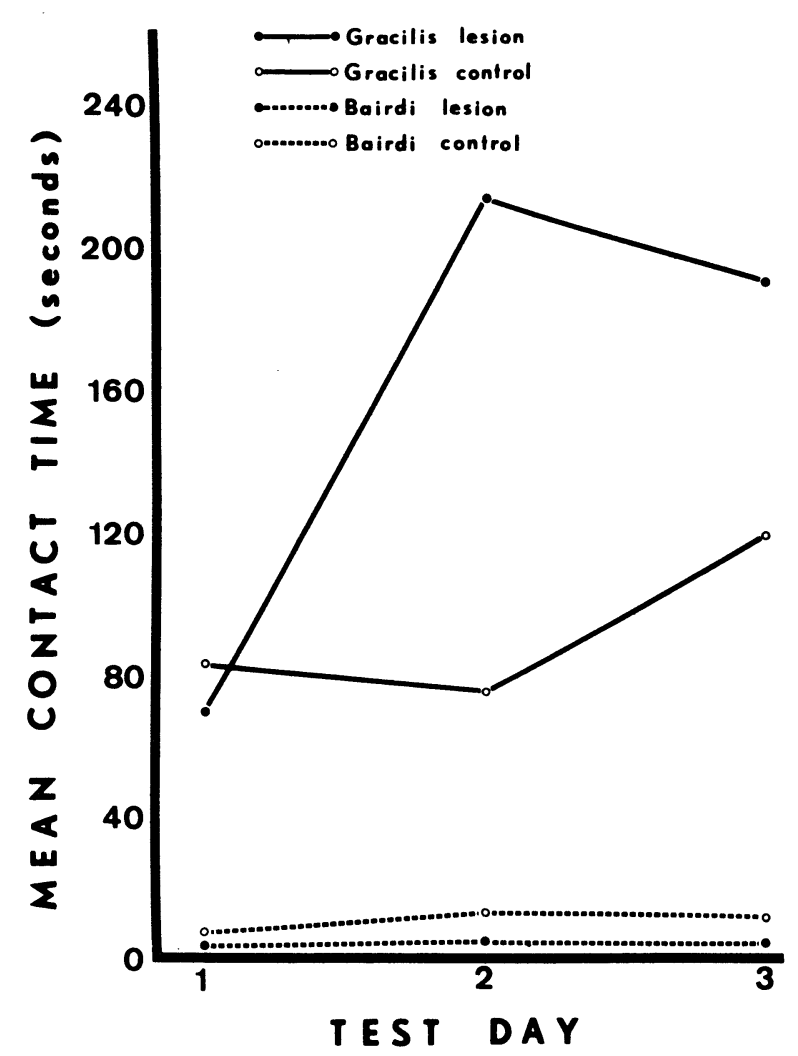

Figure 2. Mean contact times for lesioned and control bairdi and gracilis across three test sessions.

observations, both lesioned and control gracilis engaged in a curious black flipping, which was never evidenced by bairdi. On the other hand, as mentioned above, bairdi showed a much higher probability of emitting a rapid twirling behavior which often terminated in vigorous attempts to jump out of the field. Common to both subspecies were the behaviors of rearing and sniffing, jumping up along the edges of the wall, and freezing briefly in response to auditory stimuli from adjacent rooms.

Social behavior of control subjects. Considering the social behavior of the two subspecies, consistent differences were found among the groups during the 3 test days. Contact data are presented in Figure 2. As can be seen, control animals of the two subspecies evidenced great differences in the amount of time spent in physical contact. Consistent with preliminary studies, control gracilis spent an average across the 3 test days of approximately $31 \%$ of the time in contact, while control bairdi were in contact approximately $3 \%$ of the time. Due to the skewed distributions of contact scores and the extreme heterogeneity of variance, two-tailed Mann-Whitney $U$ tests were used in making all statistical comparisons between groups. Such an analysis revealed that the difference between the two control groups was statistically significant for all 3 test days $(\mathrm{p}<.05$ or less). Control gracilis typically approached one another in a relatively slow and deliberate fashion. Once contact was made, subjects engaged in mutual exploratory contact and mutual grooming for prolonged periods, often with one member of the pair on its back and the other astraddle it. Bairdi on the other hand, initiated few contacts, and in many cases, animals appeared to exert some effort to avoid being touched. Many subjects accomplished this by remaining on the perimeter of the field and circling away from any approach by the other animal. Contacts, where they occurred, often resulted from apparently inadvertent bumping when both subjects were in rapid motion, or when one subject showed sporadic aggression against the other. The latter occurred in only two bairdi pairs and did not occur in any of the gracilis pairings.

Social behavior of lesioned subjects. The effect of the septal damage was to exaggerate the basic patterns of social behavior of the two subspecies. Lesioned gracilis once contact was established, often maintained it without interruption for the remainder of the observation period. In those cases where one animal broke contact, the other member of the pair would often quickly pursue it and resume grooming. In spite of the consistency of behavior once contact was made, lesioned gracilis had some difficulty on the 1 st day in establishing such contact. This appeared to result from a lesion-induced hyperresponsiveness to sudden movements, which often caused one mouse to jump abruptly away if the other member of the pair approached too rapidly. As a result of this tendency, no group differences were found on the 1st test day $(U=5$; $\mathrm{N}_{1}=4, \mathrm{~N}_{2}=4 ; \mathrm{p}=$ n.s.). On the $2 \mathrm{nd}$ and 3rd days, however, lesioned gracilis evidenced much higher average social contact time than did their unlesioned controls. These differences were highly significant for the 2nd day $\left(\mathrm{U}=0 ; \mathrm{N}_{1}=4, \mathrm{~N}_{2}=4 ; \mathrm{p}=.025\right)$ but failed to reach commonly accepted levels of significance on the 3rd day $\left(\mathrm{U}=3 ; \mathrm{N}_{1}=4, \mathrm{~N}_{2}=4 ; \mathrm{p}=.20\right)$. The latter resulted from the failure of one of the lesioned pairs to establish contact until late in the session, again reflecting the animal's responsiveness to sudden movements. This contrasted with the behavior of the other three pairs, each of which maintained contact for virtually the entire session.

Lesioned bairdi, by contrast, showed significantly less contact time across all 3 test days when compared with their unlesioned controls ( $p<.025$ or less). Several of the lesioned bairdi pairs exhibited virtually perfect perimeter circling behavior in which each member of the pair would carefully compensate for approach movements of the other. This resulted in zero contact times and near maximum distance scores. Members of other pairs evidenced less striking avoidance of one another, but, as in the control pairs, contact largely seemed to result from inadvertent or aggressive movements on the part of one member. This strong avoidance tendency was reflected in increased perimeter scores for the lesioned bairdi, when compared with their unlesioned controls $(77 \%$ and $59 \%$, respectively; 
$\mathrm{t}=3.90, \mathrm{df}=25, \mathrm{p}<.01)$. Lesioned gracilis, however, showed no such increase when compared with their unlesioned fellows ( $73 \%$ and $72 \%$, respectively).

The distance data reflected exactly the same pattern of behaviors, albeit to a slightly less striking degree. All differences found to be statistically significant for the contact data were likewise significant for the distance data. Consequently, in the interest of brevity, these data are not presented.

Although other investigators have found some evidence for increases in intraspecific aggression following damage to the septum, no such increases were noted in the present study. One pair of lesioned gracilis emitted a single brief aggressive encounter, while members of three bairdi pairs evidenced sporadic bouts of aggression. These frequencies are comparable to those for the control pairings of each subspecies.

\section{DISCUSSION}

The results of the present study suggest that even in closely related animal species, septal lesions do not invariably increase appetitive social behavior. Clearly, as operationally defined in the present study, the probability and extent of sociability following septal damage in the two subspecies of deer mouse depended upon the particular behavior patterns characteristic of normal members of the subspecies. The highly sociable gracilis increased their social contact primarily by persevering in their normal behaviors of mutual exploration and grooming, while the relatively unsocial bairdi showed further decreases in social contact primarily by exaggerating their normal patterns of active social avoidance.

The results, and a recently reported failure by Johnson, Poplawsky, and Bielauskas (1972) to find lesion-induced increases in the social attraction of hamsters, lend no support to Glendenning's suggestion that damage to the septum enhances social interests or inclinations across a considerable range of species, apart from the manner in which such inclinations are expressed. Instead, the alterations in social behavior appear to result from deficient modulation of situationally controlled species-specific or individually acquired behavior patterns. The mechanisms through which such modulation is disrupted are not well understood, but it seems clear that in the damaged animal, environmental stimuli are unusually effective in eliciting the behaviors which have come under their control. In the present study, it was repeatedly observed that if the lesioned animals lost visual contact with one another, competing behaviors would quickly emerge and would persist until visual contact was regained. This effect was carried to the extreme in the damaged gracilis, which persisted in responding appetitively to their own reflection when confined singly to the open field. A corresponding image avoidance was not noted for bairdi, but this possibly reflects only the fact that image degradation in the galvanized metal making up the wall increased rapidly as one moved away from the wall.

These disruptive changes may result from deficient inhibitory control over prepotent behaviors as originally suggested by McCleary, through alterations in behavioral thresholds, or through some alteration in the motivational or affective components of particular stimuli. While the present results do not allow one to differentiate between these or other possible alternatives, the use of species-specific behavior patterns as interpretive variables seems to have broad applicability for further tests of neurological hypotheses.

\section{REFERENCES}

Edwards, A. L. Experimental design in psychological research. New York: Holt, Rinehart, and Winston, 1968.

Eleftheriou, B. E., \& Zolovick, A. J. The forebrain of the deer mouse in stereotaxic coordinates. Technical Bulletin 146, December, 1865, Kansas State University, Agricultural Experiment Station.

Foster, D. D. Differences in behavior and temperament between two races of the deer mouse. Journal of Mammalogy, 1959, 40, 496-513.

Glendenning, K. K. Effects of septal and amygdaloid lesions on social behavior of the cat. Journal of Comparative and Physiological Psychology, 1972, 80, 199-202.

Johnson, D. A., Poplawsky, A., \& Bielauskas, L. Alterations of social behavior in rats and hamsters following lesions of the septal forebrain. Psy chonomic Science, 1972, 26, 19-20.

Jonason, K. R., \& Enloe, L. J. Alterations in social behavior following septal and amygdaloid lesions in the rat. Journal of Comparative and Physiological Psychology, 1971, 75, 286-301.

Jonason, K. R., Enloe, L. J., Contrucci, J., \& Meyer, P. M Effects of simultaneous and successive septal and amygdaloid lesions on social behavior of the rat. Journal of Comparative and Physiological Psychology, 1973, 83, 54-61.

King, J. A. A comparison of longitudinal and cross-sectional groups in the development of behavior of deer mice. Annals of the New York Academy of Sciences, 1969, 159, 696-709.

King, J. A., Price, E. O., \& Weber, P. L. Behavioral comparisons within the genus Peromyscus. Papers of the Michigan Academy of Science, Arts, and Letters, 1968, 53, 113-136.

Latané, B. Gregariousness and fear in laboratory rats. Journal of Experimental Social Psy chology, 1969, 5, 61-69.

Latané, B. Nesbitt, P., Eckman, J., \& Rodin, J. Long and short-term social deprivation and sociability in rats. Journal of Comparative and Physiological Psychology, 1972, 81, 69-75.

McCleary, R. A. Response-modulating functions of the limbic system: Initiation and suppression. In: E. Stellar and J. M. Sprague (Eds.), Progress in physiological psychology (Vol. 1). New Y ork: Academic Press, 1966.

Poplawsky, A., \& Johnson, D. A. Open-field social behavior of rats following lateral or medial septal lesions. Physiology and Behavior, 1973, 11, 845-854.

(Received for publication October 11, 1974; revision accepted January 25, 1975.) 